\title{
Evidence that Compound $I$ is the active species in both the hydroxylase and lyase steps by which P450scc converts cholesterol to pregnenolone: EPR/ENDOR/cryoreduction/ annealing studies
}

\author{
Roman Davydov ${ }^{\mathrm{a}}$, Natallia Strushkevich ${ }^{\mathrm{b}}$, David Smil ${ }^{\mathrm{c}}$, Aliaksei Yantsevich ${ }^{\mathrm{b}}$, Andrey \\ Gilep $^{\mathrm{b}}$, Sergey Usanov ${ }^{\mathrm{b}}$, and Brian M. Hoffman ${ }^{\star}, \mathrm{a}$ \\ aDepartment of Chemistry, Northwestern University, Evanston, Illinois, USA 60208-3113 \\ bInstitute of Bioorganic Chemistry, National Academy of Sciences of Belarus, Kuprevicha Street \\ 5/2, Minsk 220141, Belarus \\ 'Structural Genomics Consortium, University of Toronto, 101 College Street, Toronto, ON, \\ Canada M5G 1L7
}

\begin{abstract}
Cytochrome P450scc (CYP 11A1) catalyzes the conversion of cholesterol (Ch) to pregnenolone, the precursor to steroid hormones. This process proceeds via three sequential monooxygenation reactions: two hydroxylations of $\mathrm{Ch}$ first form 22R-hydroxycholesterol (HC) and then 20a,22Rdihydroxycholesterol (DHC); a lyase reaction then cleaves the C20-C22 bond to form pregnenolone. Recent cryoreduction/annealing studies that employed EPR/ENDOR spectroscopy (Davydov et al. 2012 JACS 134 17149) showed that compound I (Cpd I) is the active intermediate in the first step, hydroxylation of $\mathrm{Ch}$. Herein we have employed EPR and ENDOR spectroscopy to characterize the intermediates in the second and third steps of the enzymatic process, as carried out by $77 \mathrm{~K}$ radiolytic one-electron cryoreduction and subsequent annealing of the ternary oxycytochrome P450scc complexes with HC and DHC. This procedure is validated by showing that the cryoreduced ternary complexes of oxy-cytochrome P450scc with $\mathrm{HC}$ and DHC are catalytically competent, and during annealing generate DHC and pregnenolone, respectively. Cryoreduction of the ternary complex oxy-P450scc-HC trapped at $77 \mathrm{~K}$ produces the superoxoferrous P450scc intermediate along with minor fraction of ferric hydroperoxo intermediates. The superoxo-ferrous intermediate converts into a ferric-hydroperoxo species after annealing at $145 \mathrm{~K}$. During subsequent annealing at $170-180 \mathrm{~K}$ the ferric-hydroperoxo intermediate converts to the primary product complex with the large solvent kinetic isotope effect that indicates $\mathrm{Cpd} I$ is being formed, and ${ }^{1} \mathrm{H}$ ENDOR measurements of the primary product formed in $\mathrm{D}_{2} \mathrm{O}$ demonstrate that $\mathrm{Cpd}$ I is the active species. They show that the primary product contains $\mathrm{Fe}(\mathrm{III})$ coordinated to the $20-\mathrm{O}^{1} \mathrm{H}$ of DHC with the ${ }^{1} \mathrm{H}$ derived from substrate, the signature of Cpd I reaction. Hydroperoxo ferric intermediates are the primary species formed during cryoreduction of the ternary complex
\end{abstract}

*To whom correspondence should be addressed. Brian Hoffman: Phone, (847) 491-3104; bmh@ northwestern.edu. Supporting Information $10 \mathrm{EPR} / \mathrm{ENDOR}$ and kinetics figures and information about product analysis. The Supporting Information is available free of charge via the Internet at http://pubs.acs.org. 
oxy -P450scc-DHC, and they decay at $185 \mathrm{~K}$ with a strong sKIE to form low-spin ferric P450scc. Together, these observations indicated that $\mathrm{Cpd} I$ also is the active intermediate in the $\mathrm{C} 20,22$ lyase final step. In combination with our previous results, this study thus indicates that $\mathrm{Cpd} \mathrm{I}$ is the active species in each of the three sequential monooxygenation reactions by which P450scc catalytically converts $\mathrm{Ch}$ to pregnenolone.

\section{Introduction}

The main precursor of all steroid hormones in vertebrates is pregnenolone, which is widely accepted to form from cholesterol via three successive monooxygenation reactions catalyzed by cytochrome P450scc (CYP11A1, cholesterol side-chain cleavage cytochrome P450 or cholesterol hydroxylase/C20,22-lyase). ${ }^{1-3}$ During the first step, cholesterol (Ch) is hydroxylated to 22R-hydroxycholesterol (HC), which in the second step is converted to 20a, 22R-dihydrocholesterol (DHC). Cleavage of the $\mathrm{C} 20-\mathrm{C} 22$ bond in the third step produces pregnenolone ( $\mathrm{Pr})$ and isocaproic acid. Although it has been assumed that, as with many cytochrome $\mathrm{P} 450$ reactions, each step of the Ch transformation uses compound I (Cpd I) ${ }^{4}$ as the active intermediate, ${ }^{5-12}$ to our knowledge the active oxygen species had not been experimentally established for any one of these steps until we recently began our investigations of this enzyme. Experimental test of these assumptions is of particular importance, as it has been suggested that the peroxo-ferric intermediate is the active species in the desmolase steps catalyzed by CYP 17 and $19 .{ }^{12}$

We have previously demonstrated that application of a cryoreduction/annealing method in combination with EPR/ENDOR spectroscopy can identify the active species in the catalytic cycle of heme-mono oxygenases. ${ }^{13}$ In particular, using this approach we recently showed that $\mathrm{Cpd} \mathrm{I}$ is involved in conversion of $\mathrm{Ch}$ to $\mathrm{HC}$ catalyzed by cytochrome P450scc. ${ }^{14}$ Herein application of this approach gives evidence that $\mathrm{Cpd} I$ is the active-oxygen species in P450scc-catalyzed hydroxylation of HC to form DHC, and in cleavage of the DHC C20-C22 bond.

\section{Materials and methods}

All purchased materials and reagents were of highest commercial grade available and used without further purification. DHC was synthetized as described previously. ${ }^{15}$ Human and bovine recombinant $\mathrm{P} 450 \mathrm{scc}$ were expressed, purified, and concentrated as described. ${ }^{14,16,17}$

The preparation of ternary oxy-ferrous $\mathrm{P} 450$ scc-substrate complex was performed as described previously. ${ }^{14}$ During oxygenation $20 \%$ of the ferrous P450scc converted to the ferric form; for clarity, the epr signal of the ferric form was subtracted from the EPR spectra of the cryoreduced samples. $\gamma$-Irradiation of the oxy-ferrous P450scc samples at $77 \mathrm{~K}$ and annealing at temperatures over the range $77 \mathrm{~K}-270 \mathrm{~K}$ were performed as described. ${ }^{14}$

The products DHC and pregnenolone in the cryoreduced samples was determined using GSMS analysis as described in SI. 
Concentration of the cryoreduced ferrous oxy P450scc-substrate complexes was determined by double integration of their EPR signals using $0.2 \mathrm{mM}$ substrate free low-spin ferric human cytochrome P450scc as a standard.

CW EPR spectra at X and Q bands and Q-band CW ENDOR spectra as well as low temperature UV-VIS spectra were collected and analyzed as described. ${ }^{14}$

\section{Results \\ Effect of substrates and product on EPR/ENDOR spectra of human ferric cytochrome P450scc}

To provide a reference for assigning specific states that arise during cryoreduction/annealing of the tertiary oxy-P450scc-substrate complexes, we have studied the effect of the substrates used in this work (HC and DHC) and of the product Pr on EPR and ENDOR spectra of ferric hP450scc. Expressed recombinant human substrate free (SF) ferri P450scc exhibits only a low-spin $(\mathrm{S}=1 / 2) \mathrm{EPR}$ signal, $\mathrm{g}=[2.413,2.245,1.921]$, characteristic of a hexacoordinate aqua-ferric form. ${ }^{14}$ The presence of a coordinated water in the ferric $\mathrm{hP} 450 \mathrm{scc}$ is confirmed by the observation of its exchangable ${ }^{1} \mathrm{H}$ ENDOR signals with maximum hyperfine coupling of $\approx 8.1 \mathrm{MHz}$ (Fig. S2). ${ }^{14}$

The binary complex of HC with Fe (III) P450scc also shows only a low-spin EPR signal, but with a more rhombic g-tensor, $\mathrm{g}=[2.44,2.25,1.918$,$] , as is the case of the binary complex$ $\mathrm{Fe}(\mathrm{III})$ bovine P450scc-22R HC (Fe(III) bP450scc). ${ }^{14}$ By analogy to Fe(III) bP450scc$\mathrm{HC}{ }^{14}$ this signal is assigned to the ferric heme with $\mathrm{HC}$ bound through the 22R-hydroxyl, consistent with the X-ray structure. ${ }^{17}$ The 2D field-frequency pattern of ${ }^{1} \mathrm{H}$ ENDOR signals collected across the EPR envelope of the EPR signal of the complex is considerably different from that for substrate free ferric hP450scc (Fig. S3). The spectrum from the complex collected at the field that corresponds to $\mathrm{g}_{1}=2.44$ shows two resolved ${ }^{1} \mathrm{H}$ EHDOR signals, with $\mathrm{A}=4.6$ and $8.3 \mathrm{MHz}$. The latter disappears in deuterated solvent and is assigned to the proton of the 22R-hydroxyl coordinated to Fe(III). The non-exchangeable signal with $\mathrm{A}=4.6 \mathrm{MHz}$ is assigned to the $\mathrm{H}$ atom of substrate closest to the iron(III), at either the $\mathrm{C}-22$ or $\mathrm{C}-20$ position. ${ }^{14}$

The EPR spectrum of Fe(III) hP450scc in the presence of DHC exhibits two low-spin signals with $\mathrm{g}=[2.41,2.25,1.922]$ (major) and $\mathrm{g}=[2.44,2.25,1.922]$ (minor) and a highspin $(S=5 / 2)$ signal with $g=[8.16,3.72,1.65]$. The high-spin signal is assigned to the conformational substate with penta-coordinated heme-iron(III). The low-spin signal is characteristic of hexacoordinate aqua-ferric form. The major low-spin conformer of the complex contains coordinated water as shown by the ${ }^{1} \mathrm{H}$ ENDOR spectra which exhibit a signal from exchangeable protons of the bound water that is very similar to that for sf $\mathrm{Fe}$ (III) hP450scc (not shown). The reported crystal structure of the complex Fe(III)hP450scc with DHC shows that 22R- and 20- hydroxyls are close to heme iron but without direct interaction. ${ }^{17} \mathrm{We}$ have also found that low-spin conformers of substrate-free and DHCbound hP450scc exhibit very similar ${ }^{14} \mathrm{~N}$ ENDOR spectra at $\mathrm{g}_{1}$. Thus, overall, we conclude that at equilibrium, DHC binds in the heme pocket without coordinating the heme Fe(III). 
Addition of $5 \mathrm{mM}$ Pr has no noticeable effect on the EPR signal (Fig S1), ${ }^{1} \mathrm{H}$ and ${ }^{14} \mathrm{~N}$ ENDOR, and UV-VIS spectra (not shown) of ferric hP450scc. The absence of any of these effects indicates that Pr does not bind to the enzyme and/or does not replace the aqua-ligand. In the case of bP450scc, Pr binds weakly, with $\mathrm{K}_{\mathrm{d}}=2.9 \mathrm{mM} .{ }^{18}$

\section{Cryoreduced ternary complex oxy P450scc-22R-hydroxycholesterol}

The spectrum of the cryoreduced complex trapped at 77K displays three distinct EPR signals (Fig. S4). The most intense signal A, which accounts for approximately $60 \%$ of reduced oxy-ferroheme centers, has a $\mathrm{g}_{\|}=2.102$ feature characteristic of a superoxo-ferroheme intermediate. ${ }^{19}$ Two minor signals have very similar g-tensors, $\mathbf{g}=[2.32,2.19$, nd $]$ and $\mathbf{g}=$ $\left[2.32,217\right.$, nd] (signals B and B'), characteristic of a ferric-hydroperoxo center. ${ }^{14,20,21} \mathrm{An}$ additional signal with $\mathbf{g}=[2.435,2.25, \mathrm{nd}]$ is from the ferric contamination formed during oxygenation of ferrous hP450scc-22R HC complex.

Figure 1 presents EPR spectra of the ternary oxy-hP450scc $-22 \mathrm{R}-\mathrm{HC}$ complex after $\gamma$ irradiation at $77 \mathrm{~K}$ followed by annealing of the irradiated sample at the indicated temperatures between $145 \mathrm{~K}$ and $215 \mathrm{~K}$. After annealing the irradiated sample at $145 \mathrm{~K}$ for 30s, the superoxo ferrous heme intermediate signal A significantly decreases and this process is accompanied by the concomitant increase of the hydroperoxo ferriheme signals $\mathrm{B}$ and $\mathrm{B}^{\prime}$ (Fig. S4). The intermediates $\mathrm{B}$ and $\mathrm{B}^{\prime}$ exhibit proton ENDOR signals with $\mathrm{A}_{\max } \approx$ $10.5 \mathrm{MHz}$ that disappears in deuterated solvent and is assignable to the proton of the hydroperoxo ligand (Fig. 2). During progressive annealing up to $170 \mathrm{~K}$ the hydroperoxo ferric intermediates $\mathrm{B}$ and $\mathrm{B}^{\prime}$ decay (Fig. 1), with the parallel appearance of a low-spin hexa -coordinated ferri heme species $\mathrm{C}$ with $\mathbf{g}=[2.42,2.20,1.92]$. The decay of the hydroperoxo ferric intermediates $\mathrm{B}$ and $\mathrm{B}^{\prime}$ at $150 \mathrm{~K}, \mathrm{Fig}$. 3, can be described by a "stretched exponential", ${ }^{22}$ and the decay half-time increases by a factor of over 3.5 in a $\mathrm{D}_{2} \mathrm{O} / \mathrm{d}_{3^{-}}$glycerol mixture (Fig. 3). This significant solvent KIE (sKIE) is expected for the proton assisted conversion of the hydroperoxo species B and $\mathrm{B}^{\prime}$ into Cpd I. Heterolytic cleavage of the ferriheme hydroperoxo ligand forms the Cpd I, ferryl porphyrin $\pi$-cation radical, intermediate upon protonation of the distal hydroperoxo oxygen, with the significant sKIE showing that the rate limiting step is proton delivery (Fig. 3).

The g-values of species $\mathrm{C}$, the primary product of the monooxygenation of $\mathrm{HC}$ during cryoannealing, indicate that it may be assigned to either an aqua-ferriheme state or to ferriheme coordinated to the 20-hydroxyl of DHC formed by insertion of the Cpd I oxygen atom into the $\mathrm{C} 20-\mathrm{H}$ bond. The assignment of intermediate $\mathbf{C}$ to the ferriheme-bound product DHC is confirmed by ${ }^{1} \mathrm{H}$ ENDOR spectra. Species $\mathbf{C}$ exhibits H ENDOR spectra similar to these for the complex ferric P450scc with the 22R-hydroxyl of HC coordinated to the heme iron (III) (Fig. S5). ${ }^{14}$ In particular, at $\mathrm{g}_{1}$ two features with A of $4.6 \mathrm{MHz}$ and 8.2 $\mathrm{MHz}$ can be assigned by analogy to the $\mathrm{HC}$ complex respectively to nearby $\mathrm{C}-\mathrm{H}$ proton and the 20a-hydroxyl proton of the product DHC bound through its hydroxyl to $\mathrm{Fe}(\mathrm{III}) .{ }^{14}$

This assignment is supported by the measurements with a sample prepared in D2O buffer. The 8.2 MHz signal in the primary DHC complex assigned to the 20a C-hydroxyl proton is not only seen in $\mathrm{H}_{2} \mathrm{O}$ buffer, but is largely preserved when $\mathbf{C}$ is generated in $\mathrm{D}_{2} \mathrm{O}$ buffer, Fig. 4. As shown previously for hydroxylation of bound cholesterol by the cryoreduced oxy 
P450scc ${ }^{14}$ this persistence for the primary DHC hydroxylation product implies that $\mathrm{Cpd} \mathrm{I}$ is the hydroxylating agent. ${ }^{14}$ Insertion of an oxygen atom into C-H of $22 \mathrm{R}-\mathrm{HC}$ by the ferryl ion of Cpd I generates 22R-OH with its hydroxyl group bound to Fe(III), where the hydroxyl proton is the ${ }^{1} \mathrm{H}$ that originates from the $20 \mathrm{a} \mathrm{C}-\mathrm{H}$ of substrate, and not from solvent, so remains a ${ }^{1} \mathrm{H}$ even if the reaction proceeds in $\mathrm{D}_{2} \mathrm{O}$ buffer. ${ }^{20,} 23$

As mentioned above, in the equilibrium state of the Fe(III) enzyme in the presence of DHC, neither of the 20a,22R hydroxyls coordinate to the heme iron(III). Thus, the complex between 20a hydroxyl of DHC and $\mathrm{Fe}(\mathrm{III})$ in the primary product $\mathbf{C}$ is expected to dissociate during further relaxation, forming the high spin pentacoordinate ferriheme and free DHC in the distal pocket. However, at relatively high annealing temperatures (>220K), the glycerol/buffer cryosolvent is fluid, and the $\mathrm{Fe}(\mathrm{III})$ can bind water or the high excess of substrate $\mathrm{HC}(>0.5 \mathrm{mM})$ can replace the product DHC, in which case the 22R-hydroxyl of $\mathrm{HC}$ can bind. Indeed, during annealing at $225 \mathrm{~K}$, intermediate $\mathbf{C}$ relaxes to the new state with EPR and ${ }^{1} \mathrm{H}$ ENDOR spectra characteristic of the low spin ferric hP450scc - 22RHC complex (Fig. 1, S6, S7)

Confirmation that the cryoreduced ternary ferrous oxy P450scc-22R-HC is enzymatically active, and indeed generates DHC, was obtained from product analysis of the annealed sample. The product analysis showed that the cryoreduced ternary complex annealed at $273 \mathrm{~K}$ contained $0.1 \pm 0.02 \mathrm{mM}$ DHC. Spin quantitation of the EPR signal of the cryoreduced sample annealed at $145 \mathrm{~K}$ for $10 \mathrm{~min}$ and at $180 \mathrm{~K}$ for $2 \mathrm{~min}$ (Fig. 1) revealed that during cryoreduction $0.11 \pm 0.03 \mathrm{mM}$ cryoreduced oxyheme centers forms. These observations together show that the cryoreduced enzyme is competent to quantitatively convert bound $22 R-H C$ into product, thereby validating the conclusions based on spectroscopic measurements.

\section{Cryoreduced ternary complex oxy P450scc-20,22R-dihydroxycholesterol}

EPR spectra of the ternary oxy-hP450scc-DHC complex after cryoreduction at $77 \mathrm{~K}$ and subsequent annealing of the cryogenerated intermediate(s) at indicated temperatures between 145 and $225 \mathrm{~K}$ are presented in Figure 5. The spectrum of cryoreduced complex trapped at $77 \mathrm{~K}$ displays a dominant rhombic EPR signal (A) with $\mathrm{g}=[2.29,2.19$, nd $]$ and a minor signal $\mathrm{B}$ with $\mathrm{g}=[2.36,2.21, \mathrm{nd}]$, both g-tensors are typical of hydroperoxo ferriheme intermediates. The intermediate A exhibits a strongly-coupled, solvent-exchangeable ${ }^{1} \mathrm{H}$ ENDOR signal with $\mathrm{A}_{\max } \sim 10 \mathrm{MHz}$ that is assignable to the proton of the hydroperoxo ligand (Fig. 6). The observation of the hydroperoxo ferriheme state as the predominant product of 77K cryoreduction indicates that the majority of the parent ternary oxy complexes possess a hydrogen bonding network that is tied to the precursor dioxygen ligand through an ordered water in the vicinity of the distal oxygen of the $\mathrm{O}_{2}$ ligand, and that this network supports proton delivery to the cryogenerated peroxo ligand at $77 \mathrm{~K}$ and below. ${ }^{13,14,20,24}$ as seen with oxy P450cam, oxy-heme oxygenase and oxy NOSArg. ${ }^{13,20,21,24,25}$

During progressive annealing from $145 \mathrm{~K}$ to $185 \mathrm{~K}$, the hydroperoxo ferric intermediate A decays with a parallel increase of signal $\mathrm{B}$. There also appears a weak new EPR signal with $\mathbf{g}=[2.41,2.25, \sim 1.91]($ signal $\mathrm{C})$ that is characteristic of low-spin ferric heme state, and may 
be assigned to the primary product of substrate hydroxylation (Fig. 5). Further annealing leads to decay of the signal B with concomitant increase of the product signal C (Fig. 5). The intensity of signal $C$ continues to increase until decay of B is complete (Fig. 5). During this process only small amount of high-spin pentacoordinated ferric P450scc forms. (Fig. S8)

The annealing pattern for the cryoreduced oxy bP450scc - DHC is qualitatively similar although not identical to that for the ternary complex of hP450scc (Fig. S9). Unlike hP450scc the cryoreduced ternary oxy bP450scc-DHC complex trapped at 77K exhibits approximately 3 equally populated conformational substates with $g=[2.30,2.19, \mathrm{nd}],[2.33$, $2.19, \mathrm{nd}]$ and $[2.36,2.21, \mathrm{nd}]$ characteristic of ferric hydroperoxo intermediates. During progressive annealing to $185 \mathrm{~K}$, the first two intermediates decay with concomitant growth of the $g_{\max }=2.36$ signal. At $210 \mathrm{~K}$ the $\mathrm{g}=2.36$ species relaxes to two low-spin ferriheme states with close g values of $2.44,2.24,1.89$ and $2.41,2.25,1.91$, respectively.

To gain better insight into structural features of the $g=2.36$ species and of the low-spin ferriheme states formed during annealing the cryoreduced ternary ferrous oxy P450scc-DHC complex, we have applied H ENDOR spectroscopy. The $g$ tensor of the $g=2.36$ species is suggestive of a hydroperoxo ferriheme species. ${ }^{13,21,24}$ However, the unusually large rhombicity of this EPR signal might instead suggest an interpretation in terms of a tetrahedral ferri peroxo acyl intermediate, as proposed by Ortiz de Montellano for this stage of conversion DHC to pregnenolone. ${ }^{11}$

The assignment of the $\mathrm{g}=2.36$ signal to a hydroperoxo species, not the tetrahedral intermediate, is established by EPR/ENDOR measurements. Firstly, the $\mathrm{g}=2.36$ species is formed upon cryoreduction of oxy P450scc-DHC trapped at 77K (seen best after annealing at $145 \mathrm{~K}$, Figures 5, and S9), a temperature where any chemical conversion of substrate is unlikely. Secondly, the strong sKIE for the decay of the $\mathrm{g}=2.36$ intermediate and the small sKIE for its formation during relaxation of the $\mathrm{g}=2.29$ species, are consistent with the hydroperoxo ferriheme assignment of the $\mathrm{g}=2.36$ intermediate. Finally, and definitively, the alternative assignment as an acyl intermediate is ruled out by ENDOR measurements. The $\mathrm{g}$ $=2.36$ intermediate shows the well resolved strongly coupled H ENDOR signals with Amax $\approx 10 \mathrm{MHz}$, exchangeable in deuterated solvent (Fig 8), expected for the proton of a hydroperoxo ligand coordinated to heme iron(III). A tetrahedral intermediate would be expected to exhibit ${ }^{1} \mathrm{H}$ ENDOR signals with Amax $<5 \mathrm{MHz}$ because of longer distance between nearest substrate protons and heme iron (III), and these would not exchange in $\mathrm{D}_{2} \mathrm{O}$. As the cryoreduction/annealing process converts the oxy ferroheme of the initial state to the hydroperoxo ferriheme, the peroxo ferriheme thus cannot be the reactive state.

The decay of the $\mathrm{g}=2.36$ hydroperoxo intermediate shows a large isotope effect, sKIE $\sim 6$, at $185 \mathrm{~K}$. (Fig. 7). This is expected for conversion of the hydroperoxo ferric heme intermediate into $\mathrm{Cpd} I$ through rate-limiting protonation of the distal hydroperoxo oxygen. ${ }^{13,20,21,26}$ In contrast the conversion of the $g=2.29$ species into the $g=2.36$ intermediate shows a much smaller sKIE < 2 (Fig. S10) suggesting a proton-independent structural relaxation of one hydroperoxo ferric conformer into another, more stable one. 
Upon proton delivery to the $\mathrm{g}=2.36$, hydroperoxo ferriheme intermediate it can decay by formation of Cpd I or by release of $\mathrm{H}_{2} \mathrm{O}_{2}$, depending on which oxygen atom of the hydroperoxo ligand is protonated. Protonation of the proximal oxygen and dissociation of $\mathrm{H}_{2} \mathrm{O}_{2}$ should lead to formation of high-spin pentacoordinate ferriheme species, which is not observed. Protonation of the distal oxygen favors cleavage of the $\mathrm{O}-\mathrm{O}$ bond to form $\mathrm{Cpd}$ I, ${ }^{20,21,23,27}$ which commonly does not accumulate in EPR-detectable amounts because it reacts rapidly with bound substrates or radiolytically generated free radicals. ${ }^{26} \mathrm{Cpd}$ I has been proposed to catalyze oxidative cleavage of the vicinal diol of DHC to form pregnenolone, 4-isocaproic aldehyde and molecule of water. $8,10,11,28$ This reaction is expected to form the low-spin aqua-ferriheme species as a primary product. Both the EPR spectrum of the low-spin ferriheme state which forms after loss of the g 2.36 intermediate and orientation-selective ${ }^{1} \mathrm{H}$ ENDOR spectra presented in Fig. 9 are similar to those of the aqua ferriheme center in substrate free ferric $\mathrm{P} 450 \mathrm{scc}$. Thus, these measurements support the involvement of Cpd I.

Product analysis of the cryoreduced oxy P450scc-DHC samples annealed at 273K shows that $\mathrm{Pr}$ forms during its annealing, thereby validating enzymatic activity of the cryoreduced ternary ferrous oxy P450scc-DHC complex. However, unlike the reaction with HC, which gave a quantitative yield of DHC, the experiments with DHC gave only 50\% yield of $\mathrm{Pr}$, relative to the amount of the cryogenerated reduced oxyheme centers. A possible explanation is discussed below.

\section{Discussion}

The present results provides insights into the oxy-heme center in the ternary oxy-P450scc complexes $\mathrm{HC}$ and $\mathrm{DHC}$, in addition to the key characterization of the mechanism of the second and third steps in conversion of cholesterol to pregnenolone catalyzed by P450scc.

\section{Structure of oxy-heme center}

Cyoreduction of the ternary oxy-P450scc-substrate complexes at 77K generates EPR active states that retain the conformation of the oxy precursor and thus provide sensitive EPR/ ENDOR probes of the diamagnetic oxy-ferrous precursor. ${ }^{13}$, 14, 20-22, 24, 29-32 The data presented here show that the ternary oxy-P450scc-HC complex in solution exists in at least three different conformational substates that form spectroscopically distinct intermediates upon $77 \mathrm{~K}$ reduction. EPR spectra show that radiolytic cryoreduction of the dominant conformational substate of the ternary oxy $\mathrm{P} 450 \mathrm{scc}-\mathrm{HC}$ complex at $77 \mathrm{~K}$ yields a ferrous superoxide intermediate. In the superoxo ferrous heme species an unpaired electron is localized preferentially on the superoxide ligand and this state is commonly observed in the absence of strong H-bond interaction between the superoxide ligand and its active-site environment. ${ }^{19}$

Cryoreduction of the two minor conformers of the oxy precursor generates two ferric hydroperoxo intermediates with similar EPR spectra. Experiments with a variety of oxyhemoproteins showed that proton transfer to the peroxo ligand formed by cryoreduction of the parent oxy hemoprotein at $77 \mathrm{~K}$ or below requires the presence in the parent oxy hemoprotein of a hydrogen bonded proton delivery network that includes an ordered water 
molecule hydrogen bonded to the terminal oxygen of the bound dioxygen ligand (ref ${ }^{14}$ and references therein). This water functions as a proton shuttle to the peroxo ligand generated by cryoreduction. ${ }^{19,} 20,25,33-37$

The transferred proton can originate from acid/base groups provided by amino acid residues within the active site, from bound substrate, or from water clusters connected to the active site by a proton delivery network (see ${ }^{14}$ and references therein). The nature of the bound substrate can strongly modulate this proton delivery to the cryogenerated peroxo ligand. ${ }^{21,31}$ In contrast, oxy-globins do not have such a bound water, and cryoreduction in these cases generates peroxo-ferric intermediates exclusively.

The EPR data for the cryoreduced oxy-P450scc-HC complex trapped at 77K suggest that in the dominant conformer of the oxy precursor $(\sim 70 \%)$ the bound substrate screens the dioxygen from H-bonding interaction with the polar distal environment, resulting in the cryroreductive generation of the superoxo state. In contrast, the formation of a hydroperoxo state in the minor conformational substates of the ternary oxy P450scc complex implies that the terminal oxygen of the $\mathrm{O}_{2}$ ligand $\mathrm{H}$-bonds with a proton delivery network that includes an ordered molecule of water in the active site, enabling effective protonation of a cryogenerated peroxo ferric heme at $77 \mathrm{~K}$.

The results of annealing experiments show that the superoxo ferrous species trapped at $77 \mathrm{~K}$ relaxes to hydroperoxo intermediates at relatively low temperatures, below $145 \mathrm{~K}$. This observation indicates that even under the conditions of very limited mobility at $\mathrm{T} \leq 145 \mathrm{~K}$, relatively small rearrangements within the distal pocket allow access of the distal oxygen to the $\mathrm{H}$-bonded proton delivery network, converting the ferric-superoxo sequentially into ferric peroxo, and then ferric hydroperoxo species. Presumably this conformer has a molecule of water incorporated in the vicinity of the dioxygen ligand, and it reorients at temperature above $145 \mathrm{~K}$ to establish the favorable pathway for proton transfer.

The oxy-hP450scc-DHC exhibits at least two conformational substates with different geometry of the oxyheme moiety, whereas oxy bP450scc-DHC exhibits even three conformational substates with similar populations. In all these conformational substates the cryoreduced oxyheme centers at $\mathrm{T}=77 \mathrm{~K}$ are trapped in the ferri hydroperoxo state, indicating the presence of an ordered molecule water H-bonded with the terminal oxygen of the diatomic ligand as a proton shuttle from the proton delivery array.

\section{Hydroxylation of 22R-hydroxycholesterol}

This work demonstrates that the cryoreduced ternary complex of oxy P450scc-HC, like the cryoreduced ternary oxy P450scc-cholesterol complex, ${ }^{14}$ is kinetically competent and quantitatively hydroxylates the bound substrate to form DHC during annealing. Controlled annealing of the cryogenerated ferri-hydroperoxo intermediate enables a detailed examination of successive steps in HC hydroxylation by EPR and ENDOR spectroscopy. The cryogenerated ferri-hydroperoxo intermediate $\mathbf{g}=\mathbf{2 . 3 2}$ converts completely to the primary product, species $\mathbf{g}=\mathbf{2 . 4 2}$, upon annealing at $145-170 \mathrm{~K}$. The hydroperoxo species decay with a large sKIE $>3.5$ which indicates that the rate limiting step in this process is the proton-assisted conversion of the hydroperoxo intermediate to Cpd I. 
The EPR spectrum and ${ }^{1} \mathrm{H}$ ENDOR pattern for the trapped primary product ( $\mathrm{g}=2.42$ intermediate) formed during cryoannealing in $\mathrm{H} 2 \mathrm{O}$ and $\mathrm{D} 2 \mathrm{O}$ buffers show that this state contains the product of hydroxylation by Cpd I, DHC, bound to the Fe(III) through the 20$\mathrm{OH}$ groupsince the hydroxyl proton originates from substrate through oxygen rebound mechanism during hydroxylation by $\mathrm{Cpd} \mathrm{I}$, it remains ${ }^{1} \mathrm{H}$ regardless of the isotopic composition of the solvent. Failure to detect Cpd I by EPR during this process can be accounted for by high rate of reaction with bound substrate, which prevents its accumulation. ${ }^{26}$ Finally, the hydroxyl group dissociates at higher temperatures, as expected, given that under equilibrium conditions the $20-\mathrm{OH}$ and $22 \mathrm{R}-\mathrm{OH}$ hydroxyl groups do not coordinate to the heme iron(III). ${ }^{17}$

\section{Final lyase step: C-C bond cleavage of DHC}

Annealing the cryoreduced ternary human oxyP450scc-DHC complex converts the bound substrate into pregnenolone, but with a somewhat lower yield ( $50 \%)$ than the hydroxylation of HC. This difference may be due to partial decoupling of this process because a population of the ternary oxy complexes is cryotrapped with DHC bound in an unfavorable orientation for reaction. At ambient temperature, rapid rearrangement of the binding mode would allow adequate sampling of favorable configurations for complete coupling. Controlled annealing of the cryoreduced ternary oxy P450scc-DHC complex enables detailed examination by EPR/ENDOR spectroscopy of successive step in C20-C22 bond cleavage. The dominant primary hydroperoxo ferric intermediate trapped at $77 \mathrm{~K}$ ( $\mathrm{g}_{1}=2.32$ EPR signal) relaxes to a new $\mathrm{g}_{1}=2.36$ low-spin ferric heme species upon annealing at $145-175 \mathrm{~K}$. The low solvent KIE of this conversion (Fig. S10), and the presence of a strongly-coupled $\mathrm{D}_{2} \mathrm{O}$-exchangeable ${ }^{1} \mathrm{H}$ ENDOR signal in the $\mathrm{g}_{1}=2.36$ species, indicate this conversion is associated with the relaxation of the initially formed hydroperoxo ferriheme state to a more stable conformer. Indeed, this $\mathrm{g}=2.36$ hydroperoxo ferric intermediate is the primary product of $77 \mathrm{~K}$ cryoreduction of the oxy bovine P450scc-DHC complex (Fig. S9), and a hydroperoxo intermediate with similar g-tensor components was observed during annealing of the cryoreduced tertiary oxyP450scc-cholesterol complex. ${ }^{14}$

Reaction with substrate DHC by the peroxo ferriheme state is ruled out because cryoreduction and low-temperature annealing produces the $\mathrm{g}=2.36$ hydroperoxo state. This in turn rules out the possible formation of tertiary peroxyhemiacetal-like intermediate by reaction of the peroxo-ferriheme with DHC, which has been considered, but not favored previously. ${ }^{11}$ Moreover, such a tertiary intermediate should not exhibit the strongly coupled exchangeable proton ENDOR signal shown by the $\mathrm{g}=2.36$ intermediate, which is characteristic of a hydroperoxo ligand.

Further annealing of the $\mathrm{g}=2.36$ intermediate at $\mathrm{T} \geq 180 \mathrm{~K}$ results in its conversion to a lowspin ferric-heme species whose EPR and ${ }^{1} \mathrm{H}$ ENDOR spectra are very close to these for aqua-ferric P450scc in the presence of saturating amounts of Pr. Taking into account the absence in Pr of functional groups that can coordinate to the heme iron (III), the weak perturbation by bound $\operatorname{Pr}$ of the spectroscopic properties of the equilibrium aqua-ferriheme center, and recognizing that a water molecule is a product of the lyase steps, ${ }^{8}$ we infer that the low-spin ferric intermediate trapped after complete decay of the $\mathrm{g}=2.36$ hydroperoxo 
species at $185 \mathrm{~K}$ is the primary product of enzymatic bond cleavage of DHC, in which the products Pr and isocaproic aldehyde remain in the heme pocket, while the molecule of water formed during the process ${ }^{8}$ coordinates to the heme $\mathrm{Fe}(\mathrm{III})$. The conversion of this hydroperoxo intermediate into the primary product is characterized by large solvent isotope effect (sKIE > 6) Fig. 7, comparable with that for previously reported hydroxylation of $\mathrm{Ch},{ }^{14}$ which indicates that the rate-limiting step in this process is also the proton assisted cleavage of the hydroperoxo intermediate and formation of Cpd I. ${ }^{14}$

Taken together the data implicates Cpd I in the final desmolase step of the diol cleavage. This is in good agreement with an earlier hypothesis of radical mechanism for this step of P450scc catalyzed metabolism of cholesterol. ${ }^{8}, 10,11$ According to this hypothesis the C20$\mathrm{C} 22$ bond cleavage step is depicted as proceeding through initial hydrogen abstraction from $\mathrm{C}-22-\mathrm{OH}$ by $\mathrm{Cpd}$ I to form 22-oxy radical and $\mathrm{Fe}(\mathrm{IV})-\mathrm{OH}$ species. The radical then decomposes to release one carbonyl fragment and carbon radical; the latter is intercepted by the $\mathrm{Fe}(\mathrm{IV}) \mathrm{OH}$ species to yield pregnenolone along with isocaproic aldehyde and the molecule of water bound to the regenerated ferric P450scc. This mechanism also is supported by the fact that $\mathrm{C}-\mathrm{C}$ bonds are readily cleaved (e.g. by $\left.\mathrm{HIO}_{4}, \mathrm{~Pb}(\mathrm{OAc})_{4}\right)$ if each carbon bears as oxygen substituent, as in DHC. ${ }^{5,6}$ The ability of a Cpd I analogue may catalyze oxidative cleavage of a diol was also demonstrated by Sligar and coworkers, who examined the model reaction, cleavage 1-phenyl-1,2 ethanediol by the oxo-(TPP)Cr(IV). ${ }^{28}$

\title{
Summary
}

Cryoreduction/annealing experiments in combination with EPR/ENDOR spectroscopy indicate that $\mathrm{Cpd} \mathrm{I}$ is the reactive species during $\mathrm{P} 450 \mathrm{scc}$ catalyzed hydroxylation of $22 \mathrm{R}$ hydroxycholesterol to 20,22-dihydrocholesterol and in the subsequent $\mathrm{C}$-C bond cleavage of 20,22-dihydrocholesterol to form pregnenolone. In combination with our earlier study that showed Cpd I is the reactive species in the enzymatic hydroxylation of cholesterol to form hydroxycholesterol, the present study therefore shows that Cpd I is the active species in each of the three sequential monooxygenation reactions by which cytochrome P450scc catalyzes the conversion of cholesterol in pregnenolone (Scheme I).

\section{Supplementary Material}

Refer to Web version on PubMed Central for supplementary material.

\section{Acknowledgments}

Funding: This work was supported by the NIH (GM 111097 to BMH) and by GPSI "ChemPharmSynthesis" (No $4 / 14$ to $\mathrm{SU})$.

\section{Abbreviations}

\author{
hP450sce human cytochrome P450sec(CYP11A1) \\ bP450sce bovine cytochrome P450scc \\ glycerol-d $_{3} \quad$ glycerol $(O D)_{3}$
}




$\begin{array}{ll}\text { Ch } & \text { cholesterol } \\ \text { HC } & \text { 22-hydroxycholesterol } \\ \text { DHC } & \text { 20,22-dihydroxycholesterol } \\ \text { Pr } & \text { pregnenolone } \\ \text { Cpd I } & \text { compound I } \\ \text { SKIE } & \text { solvent kinetic isotope effect }\end{array}$

\section{Citations}

1. Bernhardt, R.; Waterman, MR. Cytochrome P450 and Steroid Hormone Biosynthesis. In: Sigel, A.; Sigel, H.; Sigel, RK., editors. Metal Ions in Life Sciences. John Wiley and Sons; 2007. p. 361-396.

2. Tuckey RC. Progesterone Synthesis by the Human Placenta. Placenta. 2005; 26:273-281. [PubMed: 15823613]

3. Gilep AA, Sushko TA, Usanov SA. At the Crossroads of Steroid Hormone Biosynthesis: The Role, Substrate Specificity and Evolutionary Development of CYP17. Biochim Biophys Acta, Proteins Proteomics. 2011; 1814:200-209.

4. Groves JT, McClusky GA. Aliphatic Hydroxylation Via Oxygen Rebound. Oxygen Transfer Catalyzed by Iron. J Am Chem Soc. 1976; 98:859-861.

5. Lieberman S, Bandy L, Lippman V, Roberts KD. Sterol Intermediates in the Conversion of Cholesterol into Pregnenolone. Biochem Biophys Res Commun. 1969; 34:367-371. [PubMed: 5776386]

6. Lieberman S, Lin YY. Reflections on Sterol Sidechain Cleavage Process Catalyzed by Cytochrome P450scc. Journal of Steroid Biochemistry \& Molecular Biology. 2001; 78:1-14. [PubMed: 11530278]

7. Gustafsson JA, Rondahl L, Bergman J. Iodosylbenzene Derivatives as Oxygen Donors in Cytochrome P-450 Catalyzed Steroid Hydroxylations. Biochemistry. 1979; 18:865-870. [PubMed: 420819]

8. Larroque C, Rousseau J, van Lier JE. Enzyme-Bound Sterols of Bovine Adrenocortical Cytochrome P-450scc. Biochemistry. 1981; 20:925-929. [PubMed: 7213622]

9. Akhtar M, Wright JN. A Unified Mechanistic View of Oxidative Reactions Catalysed by P-450 and Related Fe-Containing Enzymes. Nat Prod Rep. 1991; 8:527-551. [PubMed: 1784431]

10. De Voss, JJ.; Cryle, MJ. Carbon-Carbon Bond Cleavage by P450 Systems. In: Sigel, A.; Sigel, H.; Sigel, RKO., editors. Metal Ions in Life Sciences. John Wiley \& Sons, Ltd; 2007. p. 397-435.

11. Ortiz de Montellano, PR., editor. Cytochrome P450: Structure, Mechanism, and Biochemistry. 3. Kluwer Academic/Plenum Publishers; New York: 2004.

12. Akhtar M, Wright JN, Lee-Robichaud P. A Review of Mechanistic Studies on Aromatase (CYP19) and 17 a-Hydroxylase-17,20-Lyase (CYP17). Journal of Steroid Biochemistry and Molecular Biology. 2011; 125:2-12. [PubMed: 21094255]

13. Davydov R, Hoffman BM. Active Intermediates in Heme Monooxygenase Reactions as Revealed by Cryoreduction/Annealing, EPR/ENDOR Studies. Archives of Biochemistry and Biophysics. 2011; 507:36-43. [PubMed: 20854788]

14. Davydov R, Gilep AA, Strushkevich NV, Usanov SA, Hoffman BM. Compound I is the Reactive Intermediate in the First Monooxygenation Step During Conversion of Cholesterol to Pregnenolone by Cytochrome P450scc: EPR/ENDOR/Cryoreduction/Annealing Studies. J Am Chem Soc. 2012; 134:17149-17156. [PubMed: 23039857]

15. Watanabe B, Nakagawa Y, Ogura T, Miyagawa H. Stereoselective Synthesis of (22R)- and (22S)Castasterone/Ponasterone A Hybrid Compounds and Evaluation of Their Molting Hormone Activity. Steroids. 2004; 69:483-493. [PubMed: 15246778]

Biochemistry. Author manuscript; available in PMC 2016 December 08. 
16. Lepesheva GI, Strushkevich NV, Usanov SA. Conformational Dynamics and Molecular Interaction Reactions of Recombinant Cytochrome P450scc (CYP11A1) Detected by Fluorescence Energy Transfer. Biochimica et Biophysica Acta, Protein Structure and Molecular Enzymology. 1999; 1434:31-43.

17. Strushkevich N, MacKenzie F, Cherkesova T, Grabovec I, Usanov S, Park HW. Structural Basis for Pregnenolone Biosynthesis by the Mitochondrial Monooxygenase System. PNAS. 2011; 108:10139-10143. [PubMed: 21636783]

18. Orme-Johnson NR, Light DR, White-Stevens RW, Orme-Johnson WH. Steroid Binding Properties of Beef Adrenal Cortical Cytochrome P-450 Which Catalyzes the Conversion of Cholesterol Into Pregnenolone. J Biol Chem. 1979; 254:2103-2111. [PubMed: 217878]

19. Davydov R, Satterlee JD, Fujii H, Sauer-Masarwa A, Busch DH, Hoffman BM. A SuperoxoFerrous State in a Reduced Oxy-Ferrous Hemoprotein and Model Compounds. J Am Chem Soc. 2003; 125:16340-16346. [PubMed: 14692776]

20. Davydov R, Makris TM, Kofman V, Werst DW, Sligar SG, Hoffman BM. Hydroxylation of Camphor by Reduced Oxy-Cytochrome P450cam: Mechanistic Implications of EPR and ENDOR Studies of Catalytic Intermediates in Native and Mutant Enzymes. J Am Chem Soc. 2001; 123:1403-1415. [PubMed: 11456714]

21. Davydov R, Sudhamsu J, Lees NS, Crane BR, Hoffman BM. EPR and ENDOR Characterization of the Reactive Intermediates in the Generation of NO by Cryoreduced Oxy-Nitric Oxide Synthase from Geobacillus Stearothermophilus. J Am Chem Soc. 2009; 131:14493-14507. [PubMed: 19754116]

22. Davydov R, Perera R, Jin S, Yang TC, Bryson TA, Sono M, Dawson JH, Hoffman BM. Substrate Modulation of the Properties and Reactivity of the Oxy-Ferrous and Hydroperoxoferric Intermediates of Cytochrome P450cam as Shown by Cryoreduction- EPR/ENDOR Spectroscopy. J Am Chem Soc. 2005; 127:1403-1413. [PubMed: 15686372]

23. Davydov R, Dawson JH, Perera R, Hoffman BM. The Use of Deuterated Camphor as a Substrate in ${ }^{1} \mathrm{H}$ ENDOR Studies of Hydroxylation by Cryoreduced Oxy P450cam Provides New Evidence of the Involvement of Compound I. Biochemistry. 2013; 52:667-671. [PubMed: 23215047]

24. Davydov R, Kofman V, Fujii H, Yoshida T, Ikeda-Saito M, Hoffman B. Catalytic Mechanism of Heme Oxygenase Through EPR and ENDOR of Cryoreduced Oxy-Heme Oxygenase and Its Asp 140 Mutants. J Am Chem Soc. 2002; 124:1798-1808. [PubMed: 11853459]

25. Davydov R, Chemerisov S, Werst DE, Rajh T, Matsui T, Ikeda-Saito M, Hoffman BM. Proton Transfer at Helium Temperatures During Dioxygen Activation by Heme Monooxygenases. J Am Chem Soc. 2004; 126:15960-15961. [PubMed: 15584719]

26. Davydov R, Laryukhin M, Ledbetter-Rogers A, Sono M, Dawson JH, Hoffman BM. Electron Paramagnetic Resonance and Electron-Nuclear Double Resonance Studies of the Reactions of Cryogenerated Hydroperoxoferric-Hemoprotein Intermediates. Biochemistry. 2014; 53:48944903. [PubMed: 25046203]

27. Davydov R, Razeghifard R, Im S-C, Waskell L, Hoffman BM. Characterization of the Microsomal Cytochrome $\mathrm{P} 4502 \mathrm{~B} 4 \mathrm{O}_{2}$-Activation Intermediates by Cryoreduction and Electron Paramagnetic Resonance. Biochemistry. 2008; 47:9661-9666. [PubMed: 18700729]

28. Murray RI, Sligar SG. Oxidative Cleavage of 1-Phenyl-1,2-Ethanediol by 4-Cyano- $N, N$ Dimethylaniline $N$-Oxide and Chloro(5,10,15,20-Tetraphenylporphinato)- Chromium(III) - A Model for Cholesterol Side-Chain Cleavage by Cytochrome P-450 ${ }_{\text {SCC }}$. J Am Chem Soc. 1985; 107:2186-2187.

29. Davydov R, Osborne R, Shanmugam M, Du J, Dawson J, Hoffman B. Probing the Oxyferrous and Catalytically Active Ferryl States of Amphitrite Ornata Dehaloperoxidase by Cryoreduction and EPR/ENDOR Spectroscopy. Detection of Compound I. J Am Chem Soc. 2010; 132:14995-15004. [PubMed: 20925340]

30. Davydov R, Kofman V, Nocek J, Noble RW, Hui H, Hoffman BM. Conformational Substates of the Oxyheme Centers in a and $\beta$ Subunits of Hemoglobin As Disclosed by EPR and ENDOR Studies of Cryoreduced Protein. Biochemistry. 2004; 43:6330-6338. [PubMed: 15147217]

31. Davydov RM, Chauhan N, Thackray SJ, Anderson JLR, Papadopoulou ND, Mowat CG, Chapman SK, Raven EL, Hoffman BM. Probing the Ternary Complexes of Indoleamine and Tryptophan 
2,3-Dioxygenases by Cryoreduction EPR and ENDOR Spectroscopy. J Am Chem Soc. 2010; 132:5494-5500. [PubMed: 20353179]

32. Davydov R, Matsui T, Fujii H, Ikeda-Saito M, Hoffman BM. Kinetic Isotope Effects on the RateLimiting Step of Heme Oxygenase Catalysis Indicate Concerted Proton Transfer/Heme Hydroxylation. J Am Chem Soc. 2003; 125:16208-16209. [PubMed: 14692760]

33. Kumar D, Hirao H, De VSP, Zheng J, Wang D, Thiel W, Shaik S. New Features in the Catalytic Cycle of Cytochrome P450 During the Formation of Compound I from Compound 0. J Phys Chem B. 2005; 109:19946-19951. [PubMed: 16853579]

34. Vidossich P, Fiorin G, Alfonso-Prieto M, Derat E, Shaik S, Rovira C. On the Role of Water in Peroxidase Catalysis: A Theoretical Investigation of HRP Compound I Formation. J Phys Chem B. 2010; 114:5161-5169. [PubMed: 20345187]

35. Li H, Igarashi J, Jamal J, Yang W, Poulos TL. Structural Studies of Constitutive Nitric Oxide Synthases with Diatomic Ligands Bound. JBIC, Journal of Biological Inorganic Chemistry. 2006; 11:753-768. [PubMed: 16804678]

36. Cho KB, Derat E, Shaik S. Compound I of Nitric Oxide Synthase: The Active Site Protonation State. J Am Chem Soc. 2007; 129:3182-3188. [PubMed: 17319660]

37. Guallar V, Harris DL, Batista VS, Miller WH. Proton-Transfer Dynamics in the Activation of Cytochrome P450eryF. J Am Chem Soc. 2002; 124:1430-1437. [PubMed: 11841312] 

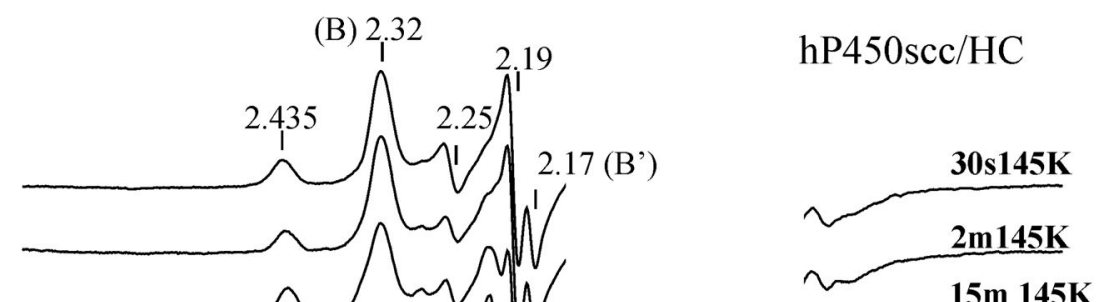

$15 \mathrm{~m} \mathrm{145K}$
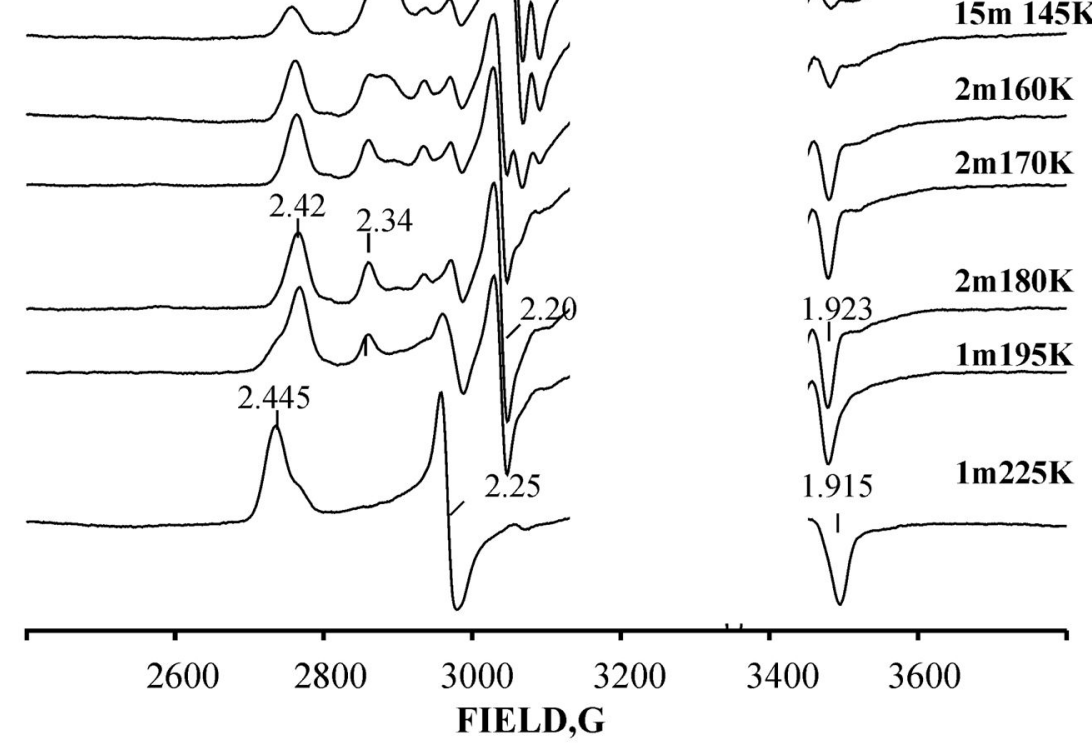

Figure 1.

EPR spectra of cryoreduced ternary oxy ferrous P450scc-22R-HC complex in 50\% glycerol/0.1 M KPi pH 7.4 and after annealing at indicated conditions. (For clarity, the EPR signal from ferric contaminant formed during the oxygenation of ferrous P450scc was subtratcted from the EPR signals of the cryoreduced ferrous oxy complex). Instrumental conditions: $\mathrm{T}=28 \mathrm{~K}$; modulation amplitude $\mathrm{A}=10 \mathrm{G}$; microwave power $10 \mathrm{~mW}$; microwave frequency 9.3. GHz. 


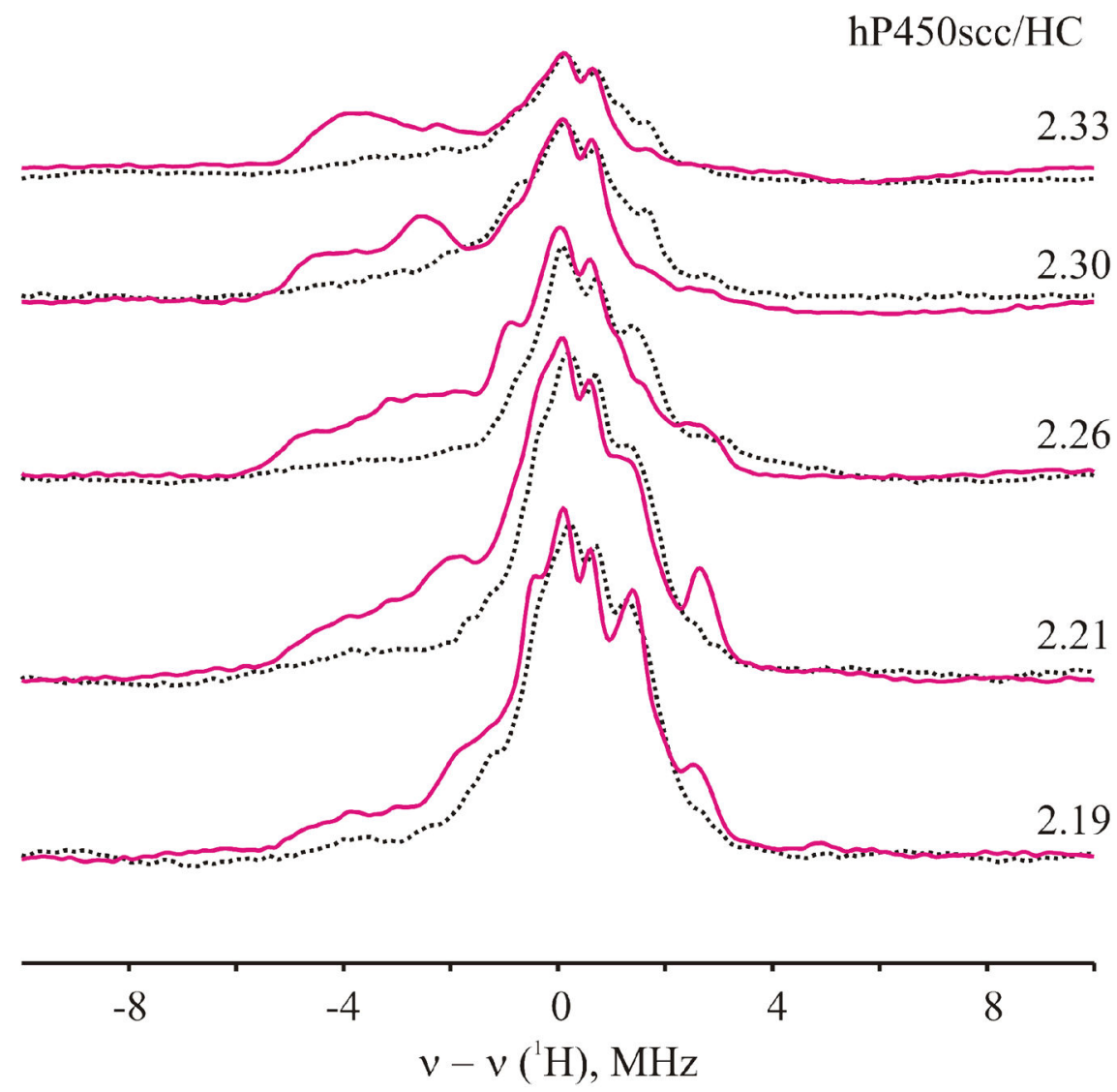

Figure 2.

2D frequency/field $35 \mathrm{GHz}{ }^{1} \mathrm{H} \mathrm{CW}$ ENDOR spectra of the cryoreduced ternary oxy ferrous $\mathrm{P} 450 \mathrm{scc}-22 \mathrm{R}$ HC complex in $50 \%$ glycerol $/ \mathrm{H}_{2} \mathrm{O}$ buffer $\mathrm{pH} 7.4$ (red) and $50 \% \mathrm{~d}-3$ glycerol/ $\mathrm{D}_{2} \mathrm{O}$ buffer $\mathrm{pH} 7.0$ (dotted black). Instrument conditions: $2 \mathrm{~K}$, modulation amplitude $2 \mathrm{G}$; rf power $5 \mathrm{~W}$, scan rate $1 \mathrm{MHz} / \mathrm{s}$; frequency bandwidth $60 \mathrm{kHz}$; average of 20 scans; microwave frequency, 34.89 . 


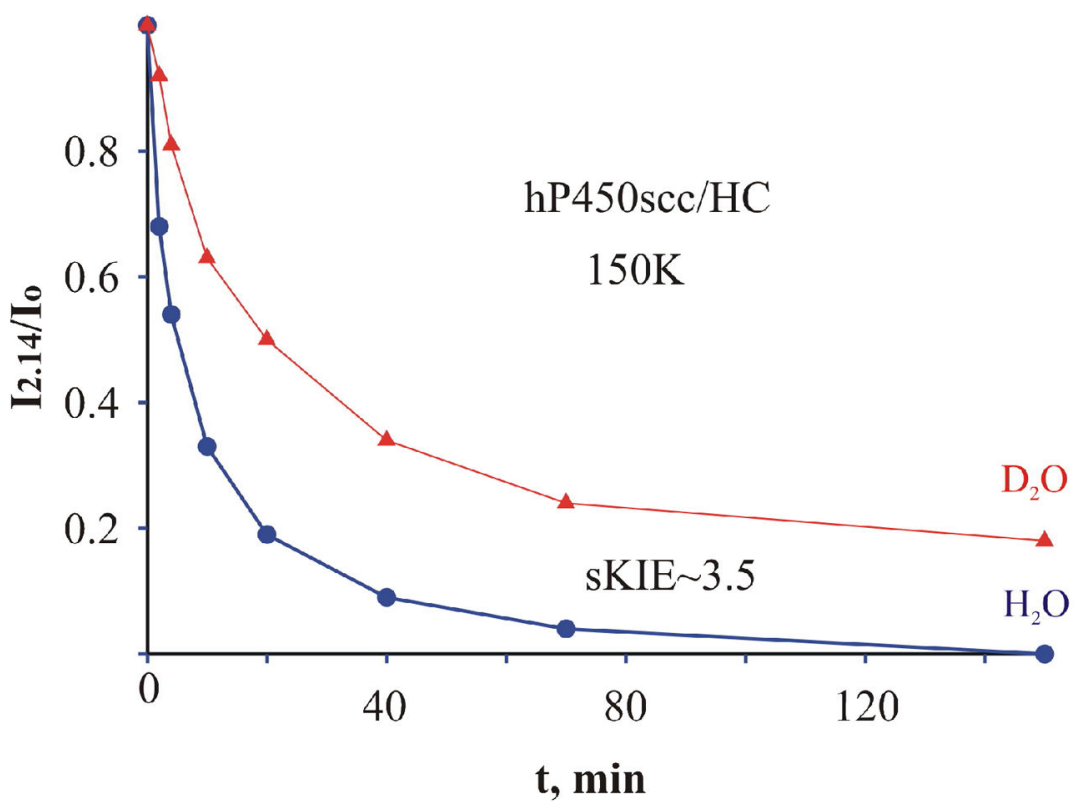

Figure 3.

Kinetics of decay of species A of the cryoreduced ternary oxy ferrous $\mathrm{P} 450 \mathrm{scc} 22 \mathrm{R}-\mathrm{HC}$ complex at $150 \mathrm{~K}$ in $50 \%$ glycerol $/ \mathrm{H}_{2} \mathrm{O}$ buffer $\mathrm{pH} 7.4$ (blue) and $50 \% \mathrm{~d}-3$ glycerol/ $/ \mathrm{D}_{2} \mathrm{O}$ buffer $\mathrm{pH} 7.0$ (red). 


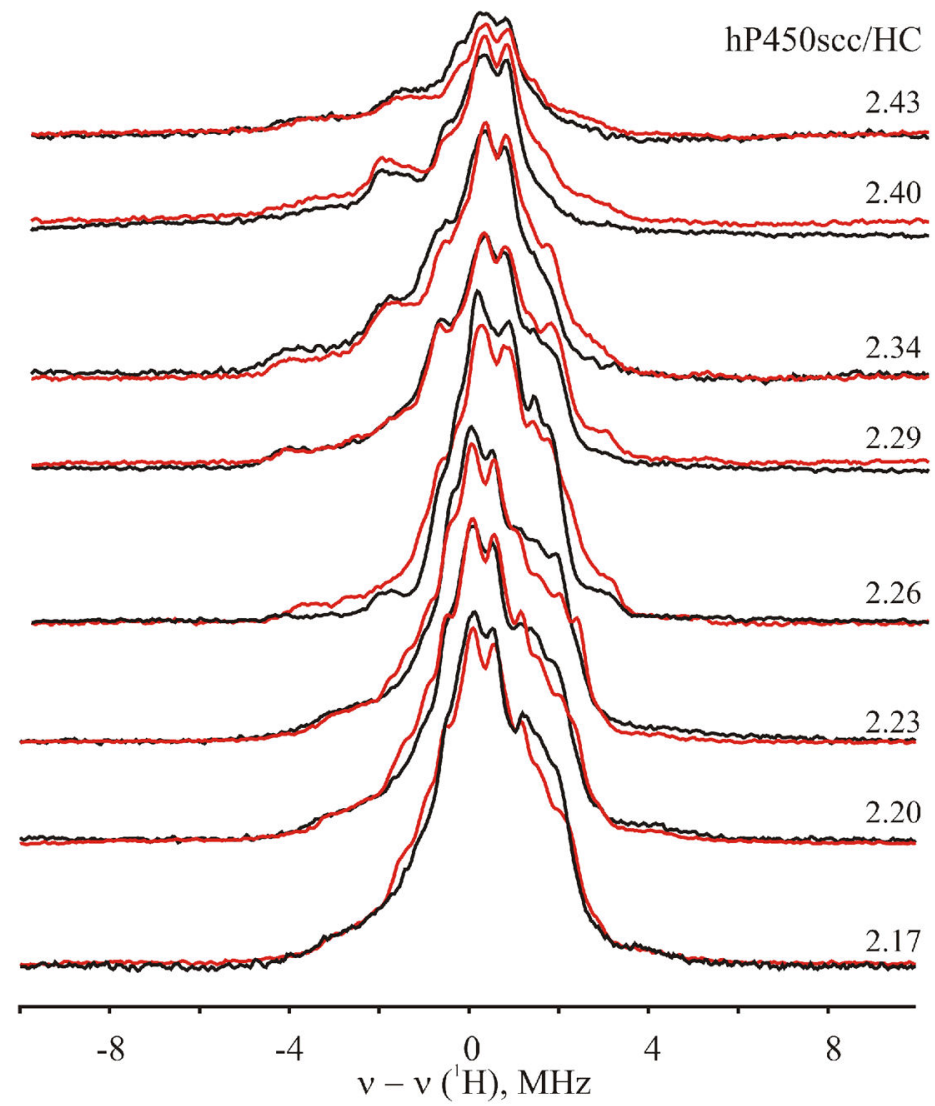

Figure 4.

2D frequency/field $35 \mathrm{GHz}{ }^{1} \mathrm{H} \mathrm{CW}$ ENDOR spectra of the cryoreduced ternary oxy ferrous P450scc - 22R HC complex annealed at $175 \mathrm{~K}$ for $1 \mathrm{~min}$ in $50 \%$ glycerol $/ \mathrm{H}_{2} \mathrm{O}$ buffer $\mathrm{pH} 7.4$ (red) and 50\% d-3 glycerol/ $\mathrm{D}_{2} \mathrm{O}$ buffer $\mathrm{pH} 7.0$ (black). Instrument conditions as in Fig2 


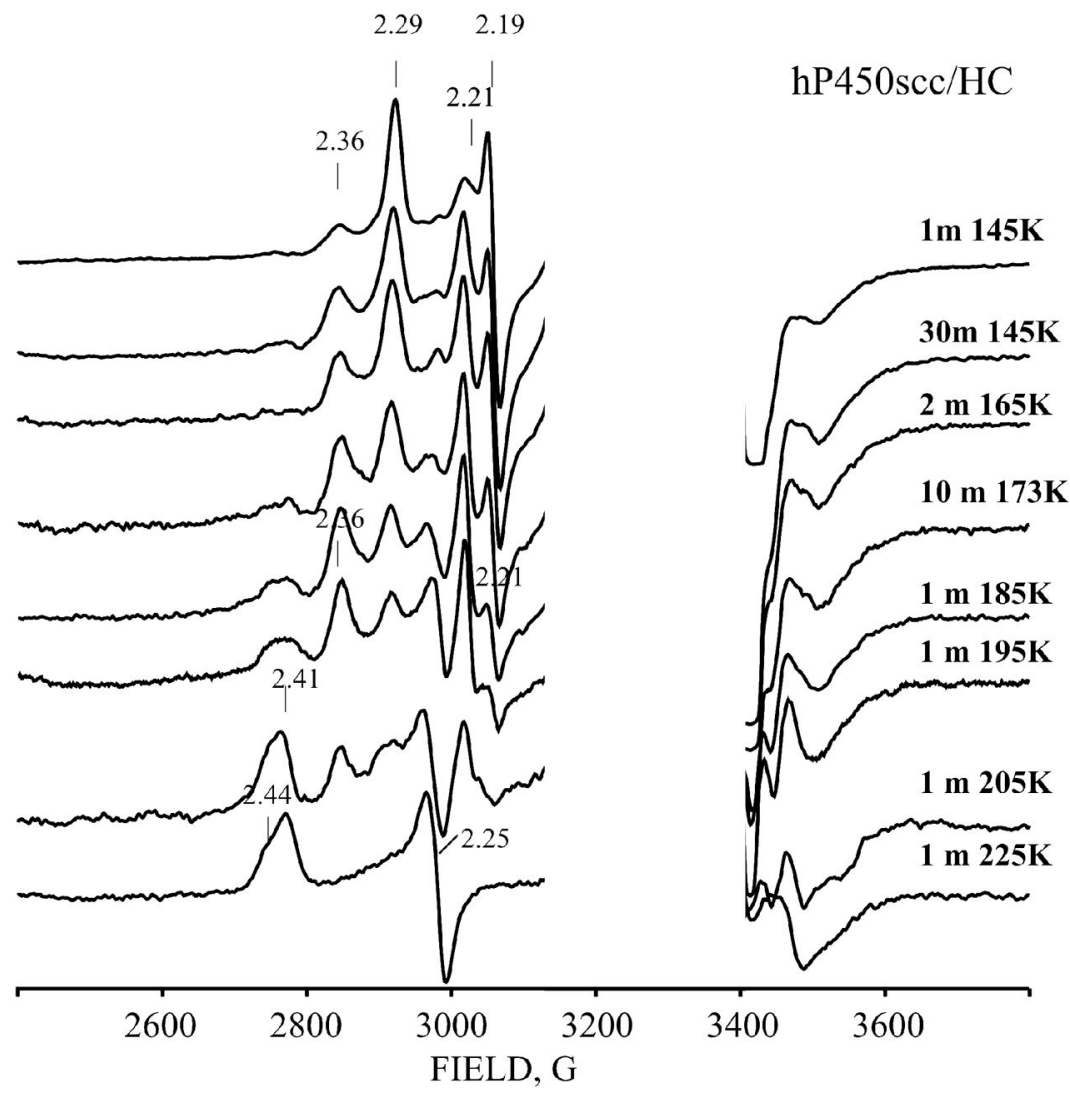

Figure 5.

EPR spectra of cryoreduced ternary oxy ferrous hP450scc-DHC complex in 50\% glycerol/0.1 M KPi pH 7.4 and after annealing at indicated conditions. Instrumental conditions: $\mathrm{T}=28 \mathrm{~K}$; modulation amplitude $\mathrm{A}=10 \mathrm{G}$; microwave power $10 \mathrm{~mW}$; microwave frequency 9.3. GHz. 

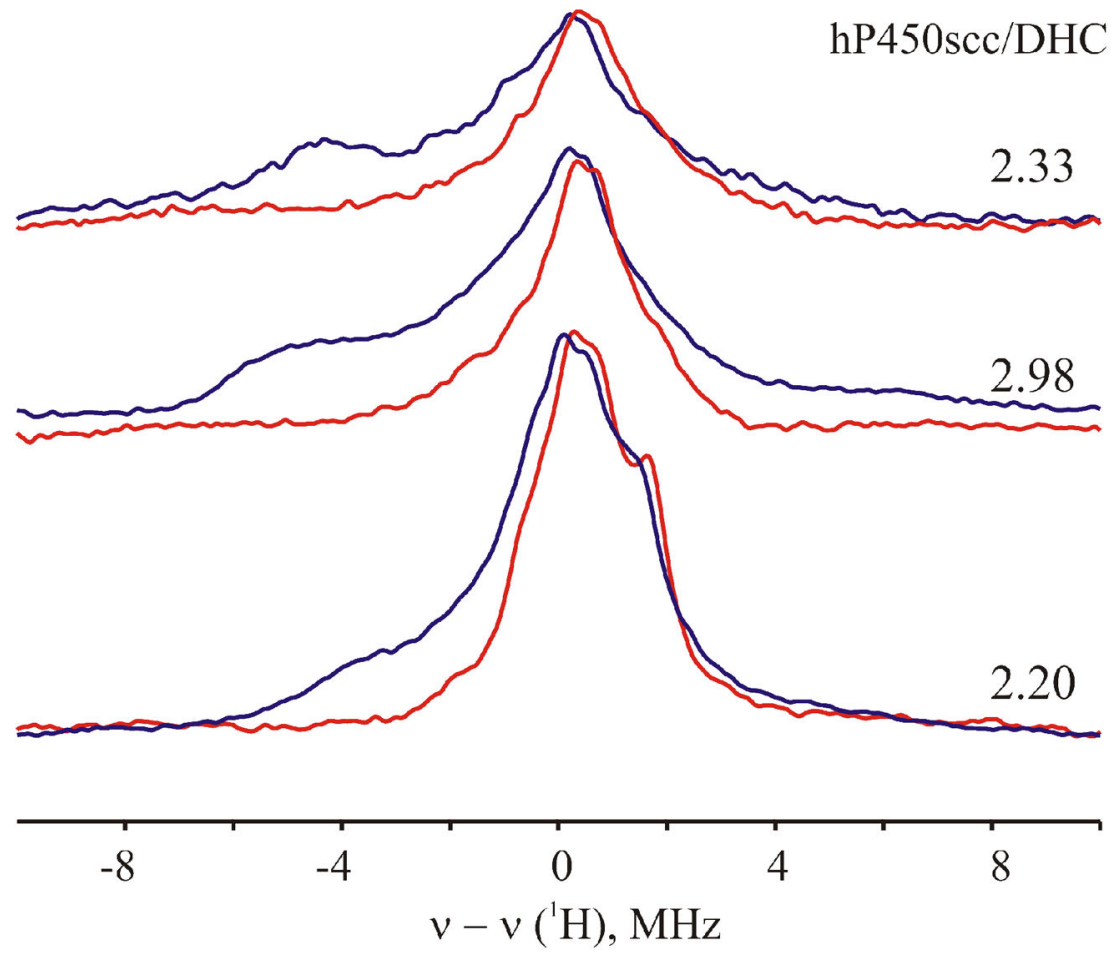

Figure 6.

2D frequency/field $35 \mathrm{GHz}{ }^{1} \mathrm{H} \mathrm{CW}$ ENDOR spectra of the cryoreduced ternary oxy ferrous P450scc - DHC complex in 50\% glycerol/ $\mathrm{H}_{2} \mathrm{O}$ buffer $\mathrm{pH} 7.4$ (blue) and $50 \% \mathrm{~d}-3$ glycerol/ $\mathrm{D}_{2} \mathrm{O}$ buffer $\mathrm{pH} 7.0$ (red). Instrument conditions: $\mathrm{T}=2 \mathrm{~K}$; modulation amplitude $2 \mathrm{G}$; rf power $5 \mathrm{~W}$, scan rate $1 \mathrm{MHz} / \mathrm{s}$; frequency bandwidth $60 \mathrm{kHz}$; average of 20 scans; microwave frequency, 34.89 . 


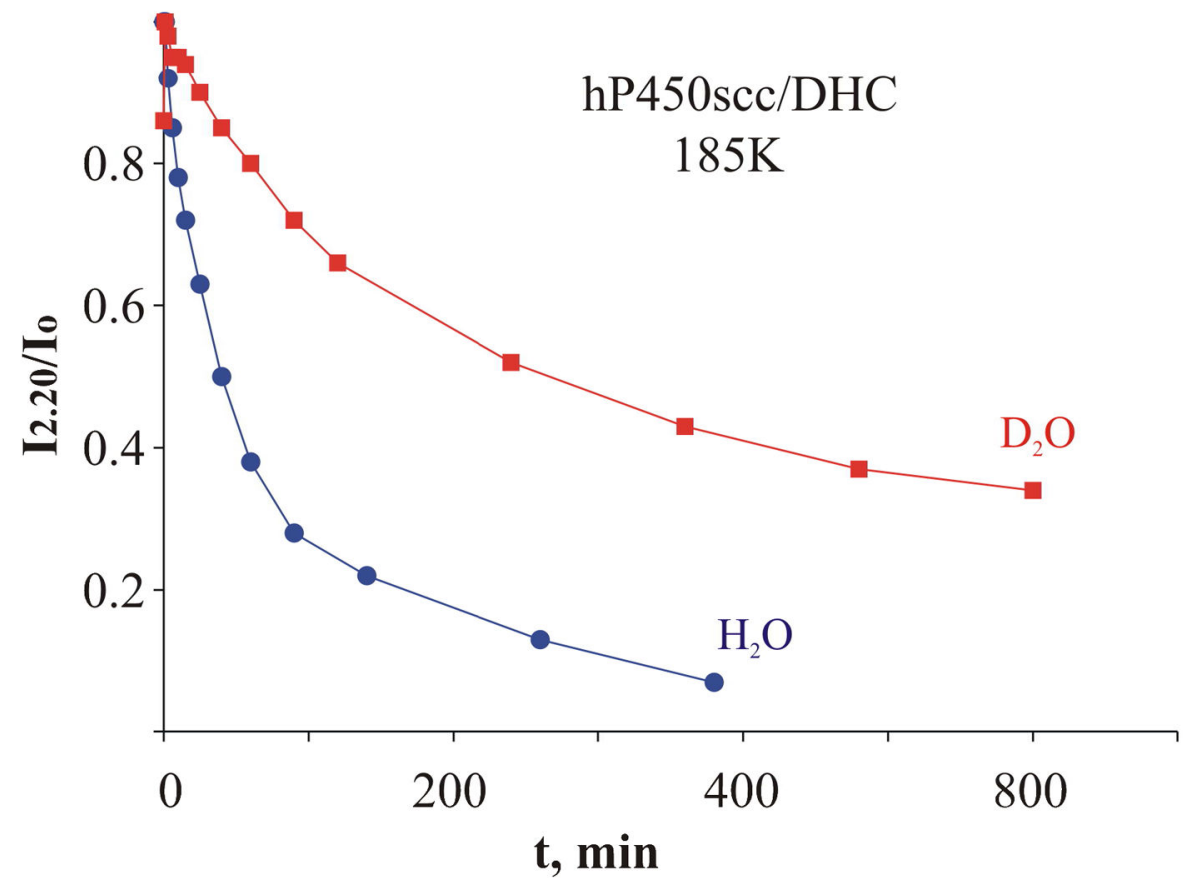

Figure 7.

Kinetics of decay of $\mathrm{g}=2.36$ species of the cryoreduced ternary oxy ferrous P450scc-DHC complex at $185 \mathrm{~K}$ in $50 \%$ glycerol $/ \mathrm{H}_{2} \mathrm{O}$ buffer $\mathrm{pH} 7.4$ (blue) and $50 \%$ d-3 glycerol/ $\mathrm{D}_{2} \mathrm{O}$ buffer $\mathrm{pH} 7.0$ (red). 


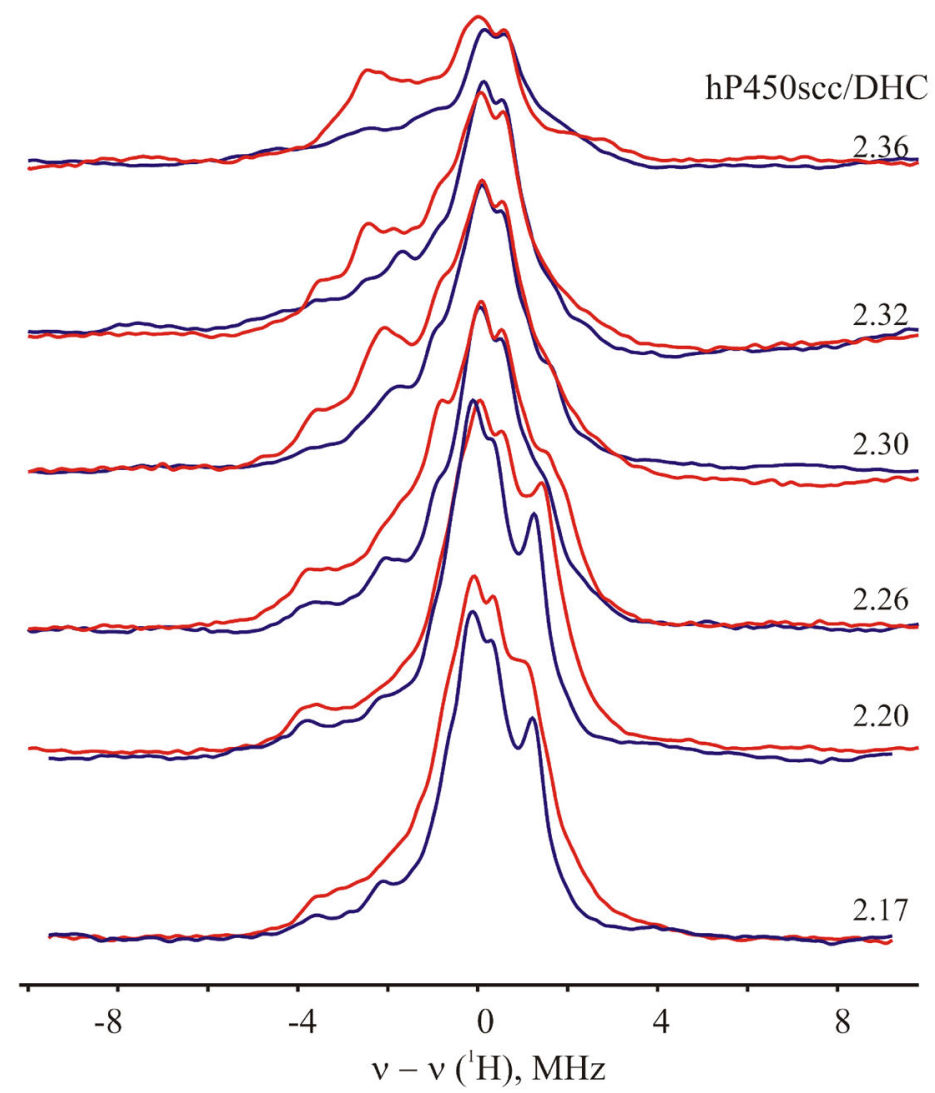

Figure 8.

2D frequency/field $35 \mathrm{GHz}^{1} \mathrm{H} \mathrm{CW}$ ENDOR spectra of the cryoreduced ternary oxy ferrous P450scc - DHC complex in 50\% glycerol/ $/ \mathrm{H}_{2} \mathrm{O}$ buffer $\mathrm{pH} 7.4$ (red) and $50 \%$ d-3

glycerol/ $\mathrm{D}_{2} \mathrm{O}$ buffer $\mathrm{pH} 7.0$ (blue) annealed at $180 \mathrm{~K}$ for $1 \mathrm{~min}$ ( $\mathrm{g}=2.36$ species). Instrument conditions: $\mathrm{T}=2 \mathrm{~K}$; modulation amplitude $2 \mathrm{G}$; rf power $5 \mathrm{~W}$, scan rate $1 \mathrm{MHz} / \mathrm{s}$; frequency bandwidth 60kHz; average of 20 scans; microwave frequency, 34.89 . 


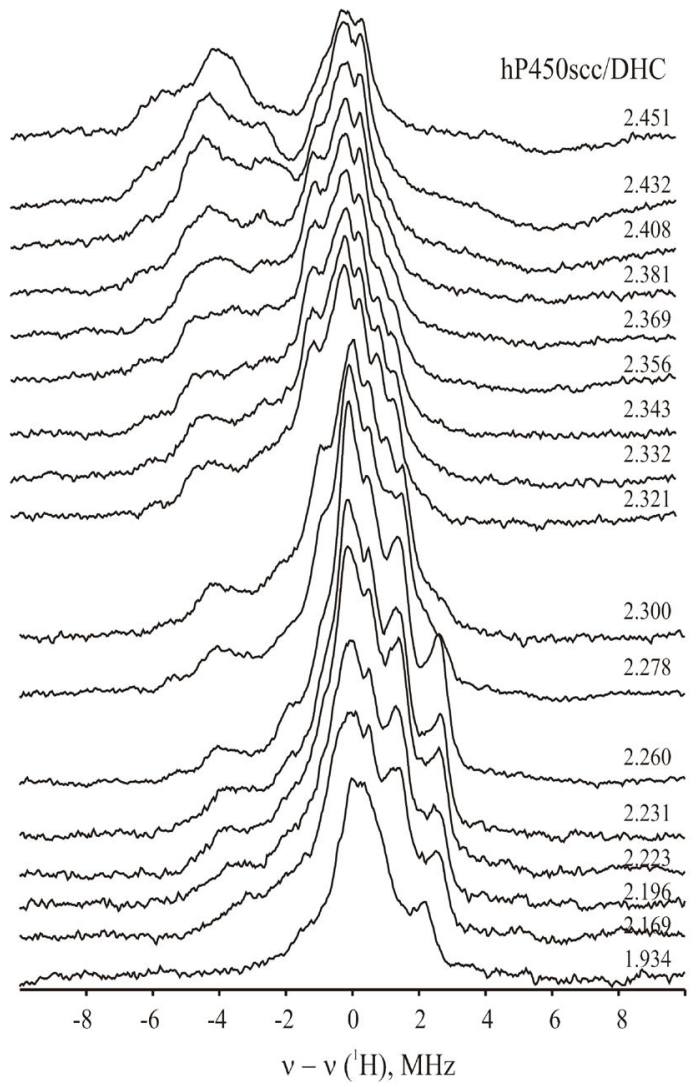

Figure 9.

2D frequency/field $35 \mathrm{GHz}{ }^{1} \mathrm{H} \mathrm{CW}$ ENDOR spectra of the cryoreduced ternary oxy ferrous $\mathrm{P} 450 \mathrm{scc}$ - DHC complex in 50\% glycerol/ $\mathrm{H}_{2} \mathrm{O}$ buffer $\mathrm{pH} 7.4$ annealed at $210 \mathrm{~K}$ for $1 \mathrm{~min}$. Instrument conditions: $\mathrm{T}=2 \mathrm{~K}$; modulation amplitude $2 \mathrm{G}$; rf power $5 \mathrm{~W}$, scan rate $1 \mathrm{MHz} / \mathrm{s}$; frequency bandwidth $60 \mathrm{kHz}$; average of 20 scans; microwave frequency, 34.89 . 

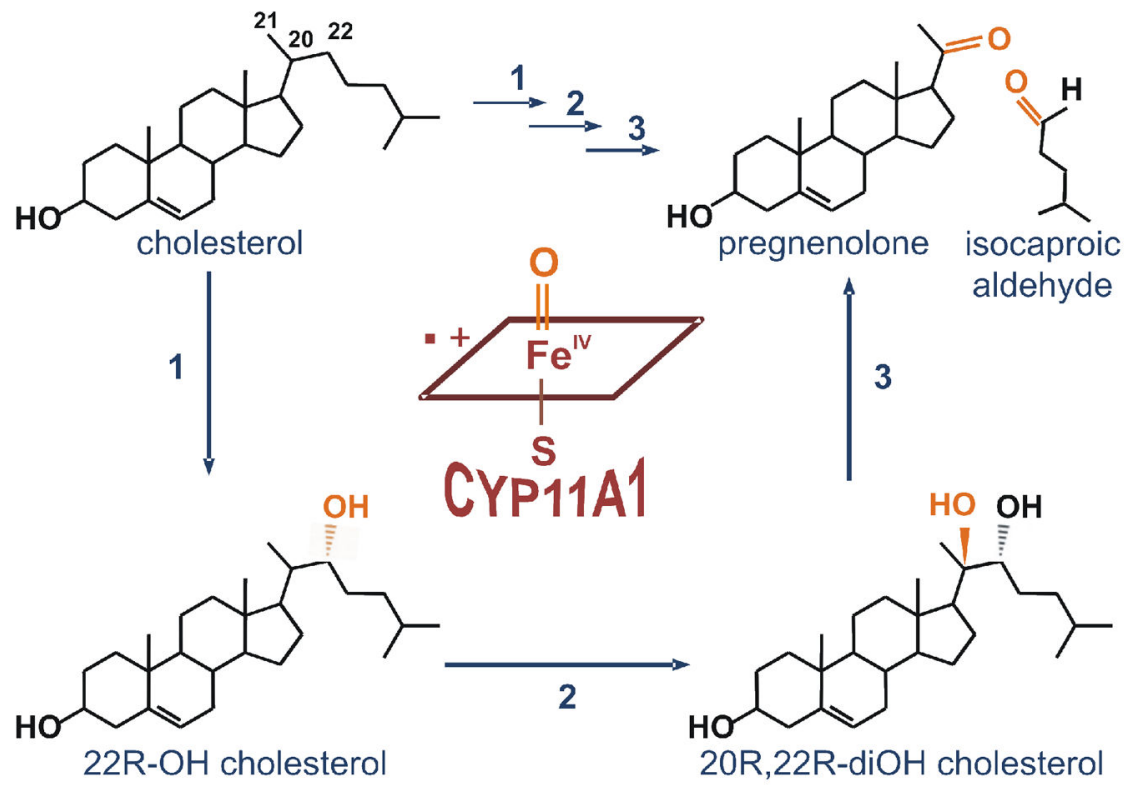

Scheme 1.

Cpd I as the active species in the metabolism of cholesterol to pregnenolone catalyzed by cytochrome P450scc. 